\title{
st \\ Quatro estudos recentes de história das ciências médicas e sociologia da saúde no Brasil
}

Regina André Rebollo

\author{
A reforma sanitária no Brasil: ecos da Primeira República \\ Luiz Antonio de Castro Santos \& Lina Rodrigues de Faria \\ Editora Universitária São Francisco, Série Ciência, Saúde e Educação \\ Bragança Paulista, 2,003, 2,4 págs.
}

\section{República dos invisíveis:}

Emílio Ribas, microbiologia e saúde pública em São Paulo (1898-1917)

Marta de Almeida

Editora Universitária São Francisco, Série Ciência, Saúde e Educação

Bragança Paulista, 2,003, 370 págs.

\section{Elites em negociação: breve história dos acordos}

entre a Fundação Rockfeller e a Faculdade de Medicina de São Paulo (1916-1931)

Maria Gabriela S. M. da Cunha Marinho

Editora Universitária São Francisco, Série Ciência, Saúde e Educação

Bragança Paulista, 2003, 1411 págs.

Estratégias da ciência: a história da Escola Paulista de Medicina (1933-1956)

Márcia Regina Barros da Silva

Editora Universitária São Francisco, Série Ciência, Saúde e Educação

Bragança Paulista, 2003, 230 págs.

Os trabalhos aqui apresentados fazem parte da "Série Ciência, Saúde e Educação" do Centro de Documentação e Apoio à Pesquisa em História da Educação da Universidade São Francisco - EDUSF. São estudos que se dedicam à compreensão do processo de institucionalização da medicina e da saúde pública no Estado de São Paulo entre o fim do século XIX e a primeira metade do século xx, explorando acervos documentais que, 
em alguns casos, esperaram demasiadamente para serem analisados. Os trabalhos de Marta de Almeida e o de Luiz Antonio de Castro Santos e Lina Rodrigues de Faria mostram dois momentos do programa da reforma sanitária implantado no Brasil e em São Paulo no período da Primeira República. Em República dos invisíveis, Marta de Almeida recupera a trajetória de Emílio Ribas à frente do Serviço Sanitário de São Paulo na luta contra a febre amarela. Em A reforma sanitária no Brasil, Luiz Antonio de Castro Santos e Lina Rodrigues de Faria mostram a atuação da Fundação Rockfeller no desenvolvimento dos serviços médico-sanitários e científicos no Brasil e o papel das elites modernizadoras nacionais na reforma sanitária.

República dos invisíveis (originalmente uma dissertação de mestrado defendida em 1998 no Departamento de História da USP) discute o processo de inserção da microbiologia nas políticas públicas de saneamento do Estado no período que vai de 1898 a 1917. O caminho escolhido pela autora foi analisar a trajetória do médico-sanitarista Emílio Marcondes Ribas (1862-1925) no enfrentamento dos problemas sanitários no Brasil e em São Paulo. A autora analisa a atuação profissional de Emílio Ribas como médico clínico, pesquisador no campo da microbiologia, com especial atenção às doenças epidêmicas tais como a febre amarela, a febre tifóide, a peste bubônica, a tuberculose e o "alastrim", e ainda como médico administrador, à frente do Serviço Sanitário de São Paulo, órgão público responsável pelo saneamento e pelas políticas de higienização do Estado. Partindo de ampla documentação histórica que inclui obras e periódicos médicos da época, documentação oficial do Serviço Sanitário, correspondências diversas, biografias e jornais, Marta de Almeida trata da dinâmica históricoinstitucional da introdução da microbiologia no Brasil, em especial em São Paulo, mostrando que as políticas de saúde pública tiveram um papel fundamental e inovador ao estabelecer novas frentes de atuação sanitária com base nas inovações microbiológicas. Ao abordar a trajetória médico-científica de Emílio Ribas, a autora, para atingir as concepções higienistas de Ribas, analisa suas instruções sanitárias para a população, em especial o pequeno ensaio escrito em 1901, $O$ mosquito como agente da propagação da febre amarela. Objetivando delinear a tensão gerada entre a medicina e o poder público, a autora analisa as estratégias de convencimento postas em prática por Emílio Ribas, a legitimação da ação sanitária e as polêmicas médicas em que se envolveu. Neste último caso, a autora parte da correspondência de Ribas com seus pares, principalmente da correspondência polêmica entre Ribas e o médico-sanitarista Artur Mendonça, um de seus oponentes mais tenazes. $\mathrm{O}$ duelo estabelecido entre os dois teve como palco "o teatro de provas das experiências", onde Ribas, Adolf Lutz, três jovens brasileiros e um italiano participaram de um conjunto de experimentos organizados pelos dois primeiros, no qual todos se deixaram picar pelos mosquitos. 
Quatro estudos regentes de história das GiênGias médicas...

O trabalho A reforma sanitária no Brasil: ecos da Primeira Republica está dividido em duas partes principais. A primeira, escrita por Lina Rodrigues (uma versão ampliada de sua dissertação de mestrado defendida em 1994 no Instituto de Medicina Social da UERJ), focaliza a fase de atuação da Fundação Rockfeller no desenvolvimento dos serviços médico-sanitários e científicos no Brasil, que se estende desde 1915 até o final dos anos 20, época de consolidação de uma etapa importante da reforma sanitária no Brasil. A autora faz uma análise dos modos pelos quais a Fundação Rockfeller procurou adaptar suas atividades às condições políticas, culturais e sanitárias do Brasil, enfatizando a questão dos graus de liberdade e das condições de negociação entre a nação brasileira e os benfeitores norte-americanos. Na segunda parte, escrita por Castro Santos, é feito um exame do papel das elites modernizadoras nacionais no processo de "sanitarização" do país. O autor apresenta o quadro político da Primeira República onde atuam as autoridades sanitárias, os aparelhos de Estado, os nacionalistas, as oligarquias agrárias, as classes médias, grupos profissionais emergentes e, por fim, a International Health Board (IHB), "precursora" da Fundação Rockfeller.

Lina Rodrigues descreve o surgimento de ideologias de reforma sanitária, centralizadas "pelo alto", isto é, articuladas pelas elites nacionais que eram movidas por objetivos não exclusivamente sociais e higienistas, mas sobretudo econômicos e políticos. Ao analisar a reforma sanitária e o pensamento social brasileiro na Primeira República a autora mostra que reformistas, médicos, higienistas e intelectuais tiverem um papel essencial no processo de "sanitarização" que seria apoiado financeiramente pela Fundação Rockfeller. Dessa ideologia nacionalista modernizadora (que via a saúde das populações brasileiras, tanto urbana quanto rural, como um elemento essencial para o progresso da Nação) resultou uma relação de negociação "entre iguais", impondo uma adaptação das atividades e intenções da Rockfeller no Brasil.

$\mathrm{Na}$ segunda parte, nas palavras do próprio autor Castro Santos, "um esforço de análise da modernização conservadora no Brasil", ele explica os rumos e o caráter geograficamente diversificado da reforma sanitária do país, bem como de sua forte impregnação ideológica durante a Primeira República. Castro Santos analisa os principais fatores do pioneirismo paulista na reforma sanitária. A escassez de mão-de-obra nas fazendas produtoras de café do Estado demandava um fluxo de imigração que pudesse estar garantido pelas boas condições de higiene e saúde; nesse sentido, o saneamento era considerado o único meio de assegurar a afluência de imigrantes. Além disso, o ambiente científico e intelectual paulista era extremamente favorável, ao contrário do Rio de Janeiro e da Bahia, que possuíam forte tradição médica monarquista (isto é, mais clínica e menos voltada para a pesquisa experimental) e a tendência para o ensino retórico. A existência de grupos positivistas menos ortodoxos em São Paulo, como o 
médico Luís Pereira Barreto e o advogado Pedro Lessa. Por fim, o movimento nacionalista encabeçado por Monteiro Lobato.

Já os trabalhos de Maria Gabriela e Márcia Regina relatam uma importante fase da história de duas escolas médicas paulistas, a Faculdade de Medicina de São Paulo e a Escola Paulista de Medicina.

Elites em negociação, inicialmente apresentada como dissertação de mestrado defendida na Universidade de Campinas em 1993, descreve os acordos estabelecidos entre a Fundação Rockfeller e a Faculdade de Medicina da Universidade de São Paulo no período de 1916 a 1931. Partindo da documentação dos arquivos da Faculdade de Medicina da Universidade de São Paulo, essencialmente da correspondência entre os membros da Faculdade e a Fundação Rockfeller, Maria Gabriela analisa tal relacionamento com vistas a compreender o processo de institucionalização da atividade médica em São Paulo durante esses quinze anos. A autora recupera a trajetória da Faculdade de Medicina e Cirurgia de São Paulo desde a sua criação, em 1912, até a associação com a Fundação Rockfeller, destacando a atuação central de Arnaldo Vieira de Carvalho na história da instituição. A autora revela que, embora o ideal da medicina científica tenha precedido o contato com a Fundação Rockfeller e a historiografia registre a importância da Faculdade de Medicina para a institucionalização da carreira médica e da atividade científica no Brasil antes da sua chegada, a associação com a Fundação Rockfeller foi fundamental para transformar a escola em centro de referência e modelo de instituição de ensino e pesquisa no país. A Fundação, pondo em prática um modelo de excelência no ensino e na pesquisa médica já testados em outros países e no próprio terreno norte-americano, define o perfil do que será considerado, na época, o melhor modelo de ensino médico de toda a América Latina e que se pautava pela exigência da aplicação de ações tais como a limitação do número de vagas em 5 o (numerus clausus), tempo integral para os docentes nas disciplinas científicas (pré-clínicas), ênfase no trabalho de laboratório concentrado num espaço próprio, organização do sistema universitário em departamentos e a vinculação do ensino a um hospital de clínicas. Atendidas tais exigências, a Faculdade de Medicina da Universidade de São Paulo recebeu um milhão de dólares da Fundação Rockfeller, responsáveis pela modernização dos espaços e da sua base material "no planalto do Araçá", tais como a criação de laboratórios e a aquisição de novos equipamentos, salas de aula, biblioteca e a construção do Hospital das Clínicas. Ao analisar os últimos cinco anos do relacionamento entre a Fundação Rockfeller e a Faculdade de Medicina, a autora mostra que no período houve uma crescente consolidação do ambiente científico fomentada por várias ações, tais como a concessão de bolsas de estudo no exterior, sobretudo nos Estados Unidos, o intercâmbio com a comunidade científica internacional através da vinda de professores estrangeiros e da criação de uma publicação, os Annaes, que além de registrar as 
Quatro estudos ReGentes de história das GiÊnGIAS MÉdicas...

ocorrências administrativas, indexou a produção científica da época. A autora revela um fato curioso: embora exista a percepção de que a contribuição da Fundação Rockfeller tenha sido importante, essa importância é reconhecida mais em termos materiais do que propriamente pelo modelo de profissionalização da atividade científica que implantou. Como a autora afirma, "nas publicações oficiais, comemorativas ou alusivas a fatos e personagens relevantes, a Fundação Rockfeller é freqüentemente reverenciada como provedora de recursos destinados à construção da infra-estrutura física, dos edifícios e laboratórios na década de 20" (p. 125). A autora chama a atenção para o fato afirmando que "é interessante observar, no entanto, que o corpo docente da escola assumiu a concepção e o discurso da Fundação Rockfeller, sem identificar a "paternidade' do modelo" (p. 125).

O estudo de Márcia Regina Barros da Silva, originalmente uma dissertação de mestrado defendida no Programa de História Social da USP em 1998, concentra-se na criação da Escola Paulista de Medicina nos anos 3 o e nos rumos por ela tomados até os anos 50 . A análise da documentação pertencente aos arquivos institucionais da Escola Paulista de Medicina, da imprensa e de periódicos da época, entre outros, possibilitou à autora a reflexão sobre a educação médica realizada em São Paulo no período que vai de 1933, ano da fundação da Escola, até a sua federalização em 1956, e “as bases em que se deu a caracterização do médico por ela formado enquanto intelectual, profissional e cientista, que buscava desempenhar um papel específico na sociedade paulista" (p. 14). Márcia Regina mostra que a Escola Paulista de Medicina foi criada por um grupo de médicos interessados em ampliar e descentralizar o ensino da medicina em São Paulo, dignos representantes de uma elite científica nacional, oriundos dos quadros das principais escolas médicas do país e que acreditavam "ser participantes de um processo que pretendia apontar um reordenamento geral da sociedade, apresentando a educação, a posse do conhecimento científico e do saber organizado em bases racionais, como fatores de ordem e de união nacional" (p. 15). Interesses individuais se mesclavam à escassez de vagas no curso de medicina da Faculdade de Medicina e Cirurgia de São Paulo que, como apontou Marinho, resultou no remodelamento didático-pedagógico impulsionado pela Fundação Rockfeller nos anos 1916-1931 e as dificuldades no ingresso da carreira docente. Assim, dois grupos tiveram a participação inicial da Escola Paulista de Medicina: estudantes interessados na ampliação do número de vagas no curso superior de medicina na Faculdade de Medicina e Cirurgia de São Paulo e profissionais "interessados em modificar sua participação no campo médico, mediante a articulação dos espaços da prática clínica, da pesquisa científica e da docência acadêmica" (p. 20). Embora tais questões tenham servido como causa motriz, outros temas foram invocados pelos partícipes do movimento, tais como a insuficiência da assistência hospitalar em São Paulo e a necessidade de ampliação e consolidação da "excelência 
científica" na formação profissional na área de atendimento médico e dos serviços de saúde oferecidos à população. Destaque especial é dado à atuação do médico Octávio de Carvalho, considerado o principal idealizador e articulador da criação de uma escola livre de medicina, bem como da análise das trajetórias profissionais individuais e da formação intelectual dos principais partícipes do movimento, entre eles Henrique Rocha Lima, Álvaro de Lemos Torres, Dorival Macedo Cardoso, Jairo Ramos e Lauro Monteiro da Cruz.

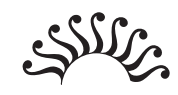

Após a rápida descrição do conteúdo de cada um dos trabalhos aqui resenhados e inspirada por sua leitura, gostaria de tecer alguns comentários que porventura possam contribuir para uma discussão acerca das possíveis abordagens metodológicas em história da ciência.

As publicações em questão partem de uma perspectiva metodológica e historiográfica que relaciona a ciência ao ambiente sociocultural no qual é produzida. Podemos dizer que tais estudos filiam-se à sociologia e à história institucional da ciência. No trabalho de Castro Santos e Rodrigues de Faria, bem como no de M. de Almeida, a ênfase é dada à dinâmica entre medicina, saúde pública e poder político; no de Barros da Silva e no de Marinho, à dinâmica histórico-social do ensino e da pesquisa médicas. Em apenas dois deles encontramos um tratamento explícito da abordagem metodológica escolhida: no de Marta de Almeida e no de Márcia Regina de Barros da Silva.

Marta de Almeida, logo no primeiro capítulo, "História das ciências no Brasil: novos itinerários para o historiador", expõe a sua filiação metodológica e historiográfica principal. Partindo de autores como Pestre, Brannigan e Kuhn, ${ }^{\mathbf{1}}$ a autora procura mostrar que "até recentemente a história das ciências introjetou a ideologia do conhecimento científico como uma entidade do saber desvinculada das complexidades sociais, pois o considerou respaldado pelos princípios da neutralidade, imparcialidade e racionalidade na busca do progresso e da verdade" (p. 22). A própria noção de "desco-

1 Dominique Pestre. Por uma história social e cultural das ciências: novas definições, novos objetos, novas abordagens. Campinas, Cadernos do Instituto de Geociências da Unicamp, v. 6, n. 1, p. 3-56, 1996; Augustine Branningan. A base social das descobertas científicas. Rio de Janeiro, Zahar, 1984; Thomas Kuhn. A estrutura das revoluções científicas. $5^{\text {a }}$ ed. Trad de B. V. Boreira et al. São Paulo, Perspectiva, 2000. 
Quatro estudos regentes de história das GiênGias médicas...

berta científica" será explicada em função da maneira como "certas realizações em ciência se constituem em descobertas e não como elas ocorreram para determinado indivíduo" (Brannigan, apud Almeida, p. 23).

A idéia de que o conhecimento científico é um produto social, integrado à dinâmica cultural e política de determinada época (segundo a autora, tese central de Kuhn), ganha apoio de dois exemplos extraídos de autores que não estão particularmente enfocando a história da ciência: Eric Hobsbawn e Pierre Bourdieu. ${ }^{2}$ De Hobsbawn, Almeida retira a idéia de que a ciência é eminentemente uma atividade humana e, portanto, sociocultural:

Os problemas que os cientistas identificam, os métodos que usam, os tipos de teorias que consideram satisfatórias em geral ou adequadas em particular, as idéias e modelos são os de homens e mulheres cujas vidas, mesmo no presente, não se restringem ao laboratório ou ao estudo (Hobsbawn, apud Almeida, p. 25).

De Pierre Bourdieu a autora extrai a idéia de que a construção do saber científico não se dá espontaneamente, mas no interior de complexas relações de disputa dentro do espaço social pela sua aceitação e consolidação, correspondendo a posições de poder (cf. p. 25).

Marta de Almeida também revê o modelo difusionista da concepção historiográfica tradicional, no qual a chamada ciência "periférica" seria apenas um reflexo da ciência produzida nos centros europeus. ${ }^{3}$

Já Barros da Silva, exatamente na última frase das considerações finais, conclui o seguinte:

Os cientistas, médicos e professores não são destituídos de ação política quando estão pesquisando, atendendo ou ensinando, estão sim realizando os seus possíveis dentro de um campo muito mais amplo de possíveis que é o da vida em sociedade, como quis demonstrar com o caso da Escola Paulista de Medicina (p. 193).

Tal tese delineia-se no primeiro capítulo:

2 Eric Hobsbawn. A era dos impérios. São Paulo, Paz e Terra, 1992; Pierre Bourdieu. O campo científico. In: Renato Ortiz (Org.). Pierre Bourdieu: Sociologia. São Paulo, Ática, 1983.

3 Almeida cita George Basalla. The spread of western science. A 3 stage model describes the introduction of modern science into any European nation. Science, 156, p. 611-22, maio de 1967 . 
A perspectiva que torna indissociável ciência e sociedade já foi tratada por alguns autores interessados, sobretudo, em discutir as bases de apreensão das ciências e de suas práticas, nas quais fosse possível explicar os diversos campos que constituem as atividades científicas, o conhecimento produzido por tais atividades, suas formas de representação e seus projetos, como processos permanentemente em construção.

Os autores utilizados para a orientação teórica de tal perspectiva são Quevedo, Pestre, Bruno Latour e Vessuri. ${ }^{4}$ Para avaliar a criação de uma instituição de ensino superior, como a Escola Paulista de Medicina, e as relações entre os agentes responsáveis pela sua criação e os processos utilizados para legitimá-la, Barros da Silva faz uso da noção de "campo científico" de Pierre Bourdieu, ${ }^{5}$ que propõe:

o entendimento do conjunto das atividades científicas e sua relação com as demais atividades sociais como um espaço de luta pela legitimação da autoridade e da competência científica de seus agentes, processo esse que iguala as relações estabelecidas no campo científico às relações estabelecidas em qualquer outro campo social (p. 13).

O núcleo da tese central que está por trás de tais autoras e de suas adesões metodológicas é o de acreditarem que, como afirma Barros da Silva citando Mascarenhas Dantes, 6 “os aspectos epistemológicos e organizacionais da atividade científica estão, por princípio, indissoluvelmente ligados" (p. 12).

Embora tal tese funcione bem no campo da história social e institucional da ciência, deve ser utilizada com cuidado na reconstrução histórica das próprias teorias científicas. Não pretendo aqui retomar o velho debate entre internalismo e externalismo, (tampouco sustentar um internalismo ingênuo a la Popper e a Escola de Viena), mas aproveitar a oportunidade para expor as minhas dúvidas e indagações.

4 Emilio Quevedo. Los estudios historicos-sociales sobre las ciencias y la tecnologia en America Latina e Colombia: balance y perspectivas. In: Seminario: Las ciencias sociales en la historiografia de lengua española. ICFES, Cartagena, julho de 1990; La institucionalización de la educación médica en la América hispano-lusitana. Quipu, Revista Latinoamericana de Historia de las Ciencias y la Tecnologia, México, 10, 2, p. 165-88, mayo-ago. 1993; Hebe C. Vessuri. Perspectivas recientes en el estudio social de la ciencia. Interciencia, 16, 2, p. 6o-8, mar.-abr. 1991; Bruno Latour. Ciência em ação. São Paulo, UNESP, 2000.

5 Pierre Bourdieu. A economia das trocas simbólicas. 3a ed. São Paulo, Perspectiva, 1992; e O campo científico. In: Renato Ortiz (Org.). Sociologia. São Paulo, Ática, 1994.

6 Maria Amélia Mascarenhas Dantes. Fases da implantação da ciência no Brasil. Quipu, Revista Latinoamericana de Historia de las Ciencias y la Tecnologia, México, 5, 2, p. 265-75, mayo.-ago. 1988. 
Quatro estudos regentes de história das GiênGias médicas...

Afirmar que o conhecimento científico e todos os aspectos epistemológicos aí envolvidos são influenciados ou até mesmo determinados pelas condições institucionais ou organizacionais é simplesmente negar a autonomia do pensamento científico ou, pelo menos, colocá-lo num segundo plano. Há um aspecto do conhecimento científico, ainda que considerado como um fato social, que é irredutível às explicações socioinstitucionais. Explico: o conhecimento científico é produzido e compartilhado, num primeiro momento, por uma comunidade acadêmica fechada em si mesma, uma comunidade de sperts que preza por sua autonomia e que mantém um conjunto de valores, normas e regras (que não são necessariamente os mesmos expressos na prática científica e nas instituições científicas) que são compartilhadas por todos aqueles que pertencem à tal comunidade. Entre os valores compartilhados estão os chamados valores cognitivos, a saber, a adequação empírica das teorias, a consistência da teoria, a simplicidade (clareza conceitual, elegância, economia etc.), a fecundidade teórica, o poder explicativo e o grau de verdade e certeza de suas afirmações. ${ }^{7}$ Na prática e nas instituições científicas, os valores sociais e morais possuem tanto peso quanto os valores cognitivos, e é somente por esse motivo que podemos sustentar uma abordagem socioinstitucional da ciência. Com isso quero tão somente salientar o poder heurístico das reconstruções racionais (no sentido lakatosiano) para a compreensão da ciência e do conhecimento científico. Para todos aqueles que fazem uma história da ciência filosoficamente orientada, esse poder explicativo é uma poderosa ferramenta de trabalho, sem a qual podemos apenas falar parcialmente sobre a ciência e o conhecimento científico.

Regina André Rebollo

Pesquisadora do Projeto Temático "Estudos de filosofia e história da ciência" da FAPESP, pós-doutoranda do Departamento de Filosofia da Universidade de São Paulo. haniger@usp.br

7 Hugh Lacey. Valores e atividade científica. Trad. de M. B. de Oliveira et al. São Paulo, Fapesp/Discurso Editorial, 1998. 